\title{
A Systematic Approach to Identify Sources of Abnormal Interior Noise for a High-Speed Train
}

\author{
Jie Zhang $(\mathbb{D}$, Xinbiao Xiao, Xiaozhen Sheng, Zhihui Li, and Xuesong Jin
}

State Key Laboratory of Traction Power, Southwest Jiaotong University, Chengdu 610031, China

Correspondence should be addressed to Xuesong Jin; xsjin@home.swjtu.edu.cn

Received 26 February 2018; Accepted 15 April 2018; Published 20 May 2018

Academic Editor: Cristina Castejón

Copyright (C) 2018 Jie Zhang et al. This is an open access article distributed under the Creative Commons Attribution License, which permits unrestricted use, distribution, and reproduction in any medium, provided the original work is properly cited.

\begin{abstract}
A systematic approach to identify sources of abnormal interior noise occurring in a high-speed train is presented and applied in this paper to resolve a particular noise issue. This approach is developed based on a number of previous dealings with similar noise problems. The particular noise issue occurs in a Chinese high-speed train. It is measured that there is a difference of $7 \mathrm{~dB}(\mathrm{~A})$ in overall Sound Pressure Level (SPL) between two nominally identical VIP cabins at $250 \mathrm{~km} / \mathrm{h}$. The systematic approach is applied to identify the root cause of the $7 \mathrm{~dB}(\mathrm{~A})$ difference. Well planned measurements are performed in both the VIP cabins. Sound pressure contributions, either in terms of frequency band or in terms of facing area, are analyzed. Order analysis is also carried out. Based on these analyses, it is found that the problematic frequency is the sleeper passing frequency of the train, and an area on the roof contributes the most. In order to determine what causes that area to be the main contributor without disassembling the structure of the roof, measured noise and vibration data for different train speeds are further analyzed. It is then reasoned that roof is the main contributor caused by sound pressure behind the panel. Up to this point, panels of the roof are removed, revealing that a hole of $300 \mathrm{~cm}^{2}$ for running cables is presented behind the red area without proper sound insulation. This study can provide a basis for abnormal interior noise analysis and control of high-speed trains.
\end{abstract}

\section{Introduction}

Interior noise of a high-speed train greatly affects vehicles' ride comfort and therefore is one of the key issues to be addressed in the design, manufacture, and operation of high-speed trains [1-3]. With the increasing speed of highspeed trains, interior noise becomes more important and difficult to deal with. Two things must be focused on when studying interior noise of a high-speed train, one being the mechanisms of noise generation (root sources) and the other being the paths of noise propagation/transmission. As shown in Figure 1, the major sources of a high-speed train are wheel/rail rolling noise, aerodynamic noise, and equipment noise. Characteristics of these sources are closely related to the running speed of the vehicle [4]. These sources are exterior to the train, but they can develop into interior noise through air-borne and structure-borne transfer paths [1]. For interior noise analysis and control of high-speed trains, attention should be given to both sources and transfer paths.
Remington [5] and Thompson and Gautier [6] conducted comprehensive research on the mechanisms and predictions of wheel/rail rolling noise, promoting low wheel/rail noise technology. Kitagawa and Nagakura $[7,8]$ studied the aerodynamic noise generated by SHINKANSEN trains. They found that the aerodynamic noise generated from the upper parts of trains can be considerably reduced by smoothing the surface of the train, and the noise source at the front bogie of the leading car is much stronger than that at other bogies. Mellet et al. [9] investigated the contribution of aerodynamic/rolling noise for high-speed trains. They concluded that whether rolling noise is the most important source depends not only on the train speed, but also on the wheel/rail surface conditions. Noh [10] used a microphone array system to identify the noise source of a high-speed train and found that the main noise sources are the intercoach spacing, wheels, and pantograph, when the train is running at $390 \mathrm{~km} / \mathrm{h}$. Soeta and Shimokura [11] researched the effects of noise sources on the interior noise characteristics in a number of types of trains. 


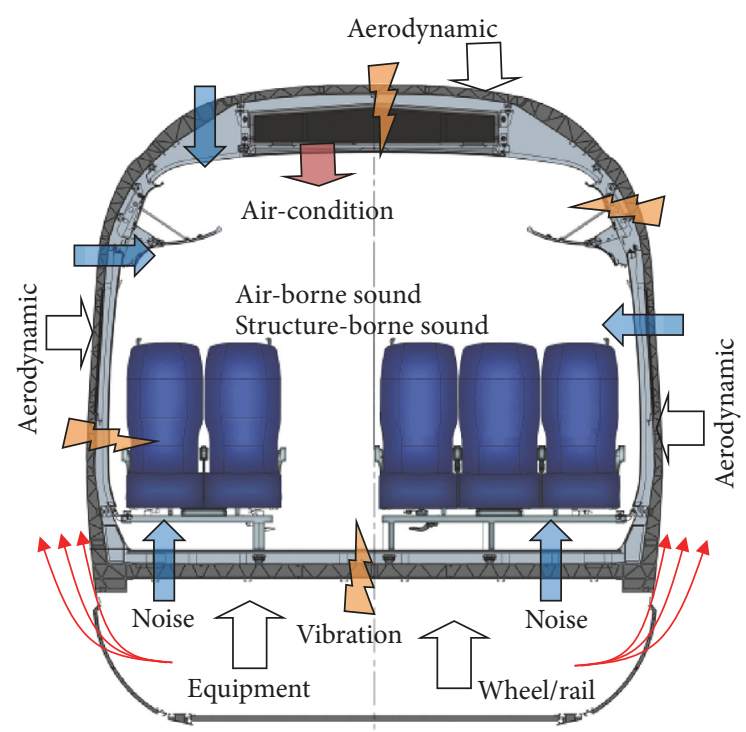

FIGURE 1: Sources and noise transfer paths of a high-speed train.

They found that, compared with wheel/rail rolling noise, impact noise had larger components at frequencies below $500 \mathrm{~Hz}$, while curve squeal noise had larger components at frequencies between $125 \mathrm{~Hz}$ and $500 \mathrm{~Hz}$. Park et al. [12] measured the noise in passenger compartments of highspeed trains operating in Korea under various conditions and proposed a new method to quantify the annoyance based on a number of sound quality metrics. Fan et al. [13] used the sound intensity and partial coherence methods to identify interior noise sources on a high-speed train and found that the major interior noise source is structural-borne sound radiated by floor vibration. Chu et al. [14] proposed a new convolution formulation for Spherical Harmonics Beamforming (SHB) with solid spherical arrays. It was found that deconvolution was realized to get clear maps for sources in 3D cabin environments. Yang et al. [15] created novel delay and sum (DAS) and functional delay and sum (FDAS) algorithms for 3D acoustic source identification with solid spherical arrays. Ström [16] used the Operational Transfer Path Analysis (OTPA) technique to rank transmissions to interior noise of different paths within a high-speed train bogie. They found that the three important paths in the frequency range analyzed are air-borne transfer path, the traction rod, and the yaw dampers.

In summary, significant researches have been made into high-speed train noise generation and propagation. Results from such research are beneficial to the design of low noise trains. With all the knowledge about noise sources and transfer paths, the interior noise is under control. Modelling during train design is performed to guarantee the acoustic comfort. However, special interior noise problems, normally called "abnormal interior noise" [17], still occur sometimes during the operation of high-speed trains. They are largely related to product defects and bad wheel/track conditions, although occasionally rooted from design. If issues do occur, engineers from the train manufacturer are normally contacted with and required to resolve the issues as quickly

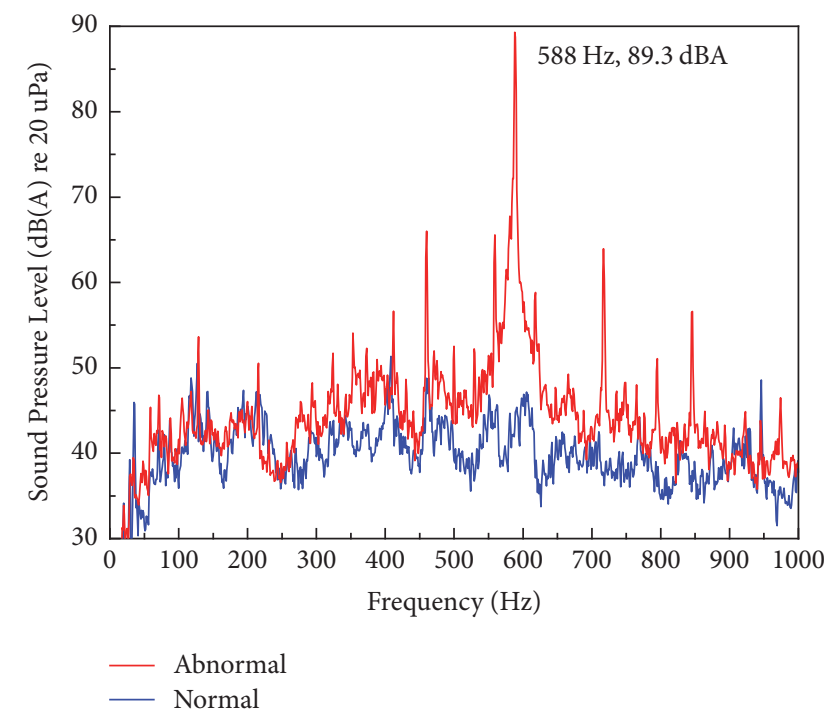

Figure 2: Normal noise (blue) and abnormal noise (red).

as possible. It is therefore equally important to establish an effective, measurement-based, approach and procedure which can be used to identify sources and transfer paths of such abnormal interior noise.

This paper presents such a measurement-based approach by performing a detailed investigation into a particular "abnormal interior noise" issue occurring in a Chinese highspeed train running at $250 \mathrm{~km} / \mathrm{h}$. In Section 2, examples of abnormal interior noise issues are given and the approach is described as a working procedure with brief explanations. In Section 3, after a description of the particular noise issue, the approach is applied to identify the root causes of the issue, including generation mechanism and transmission paths. The paper is concluded in Section 4.

\section{Description of the Systematic Approach}

As the term "abnormal interior noise" indicates, the noise issue must be easily noticed by non-NVH professionals such as passengers and train staff, perceived as unusual in terms of loudness and characteristics, and felt to be annoying. Figure 2 gives an example which can be classified as "abnormal interior noise."

Two noises shown in Figure 2 were measured, respectively, in two coaches of the same design. The red one is called "abnormal interior noise" since it has a dominant single frequency peak which represents a very high overall Sound Pressure Level (SPL). The most effective approach to identify the root cause of abnormal noise is performing well planned measurements on the train running at the same condition as that when the noise issue was observed, combined with proper data analysis. In general, the following procedure should be excised.

2.1. Examples of Abnormal Interior Noise Issues. From previous dealings with interior noise issues of high-speed trains, it is found that an abnormal interior noise issue can be very 


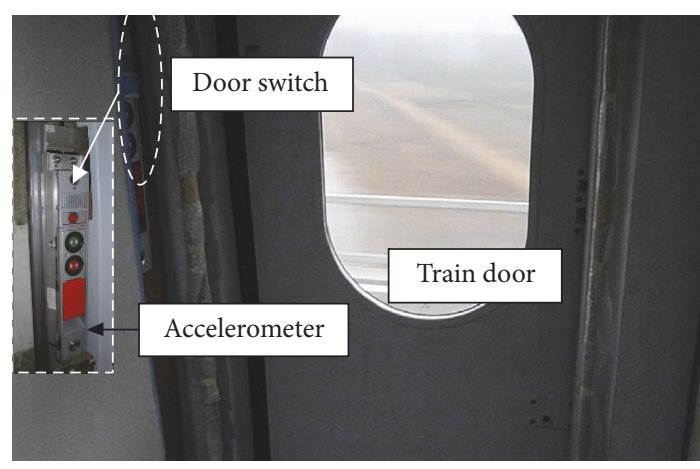

FIGURE 3: Abnormal interior noise generated by the door switch.

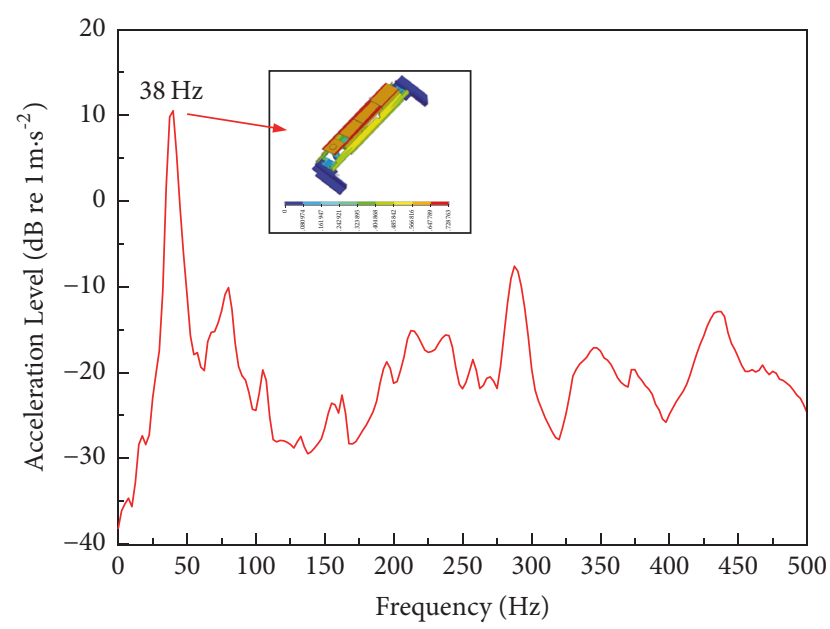

FIGURE 4: Frequency spectra of acceleration of the door switch.

complex in terms of generation mechanism and transmission path. There are quite a few types of such issues which can be illustrated: they can be of broadband or just at a single frequency; the problematic frequency may be related to train speed or just remains nearly constant; the noise source may be localized or from a large area of the train; they can be caused by structural resonance or simply by sound leakage, and so on.

For example, (1) abnormal noise is generated by the door switch assembly as indicated in Figures 3 and 4 . The noise/vibration is a single frequency which is related to train speed. The noise is radiated by the structural resonance of the door switch assembly which is in turn excited by the first order of the wheel out-of-round wear at $380 \mathrm{~km} / \mathrm{h}$. (2) Abnormal interior noise occurred at the ends of a coach [18] at a single frequency as indicated in Figures 5 and 6. The problematic frequency is related to train speed. The root cause is the sleeper passing of the train at $250 \mathrm{~km} / \mathrm{h}$ which excites one of the acoustic modes at the coach end through vibrations of the floor and the sidewall. (3) Abnormal interior noise occurred in a driver's cab of a high-speed train as indicated in Figure 7. It is of broadband and the problematic frequencies are independent of train speed. The source is related to the air-conditioning and the generated noise propagates into the interior via airflow in the ducts.

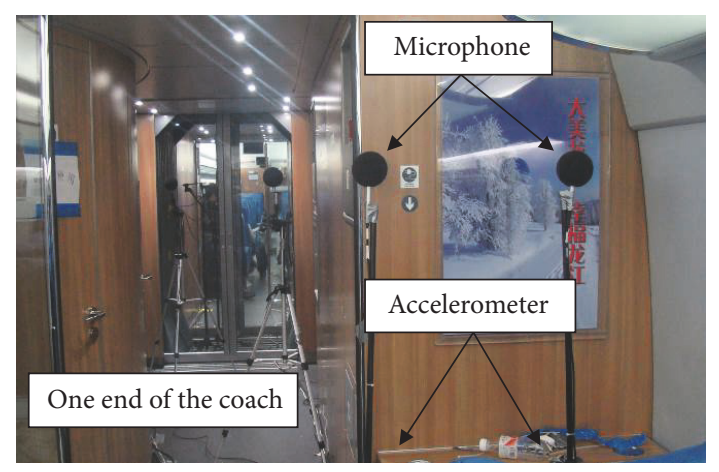

Figure 5: Abnormal interior noise at one end of the coach.

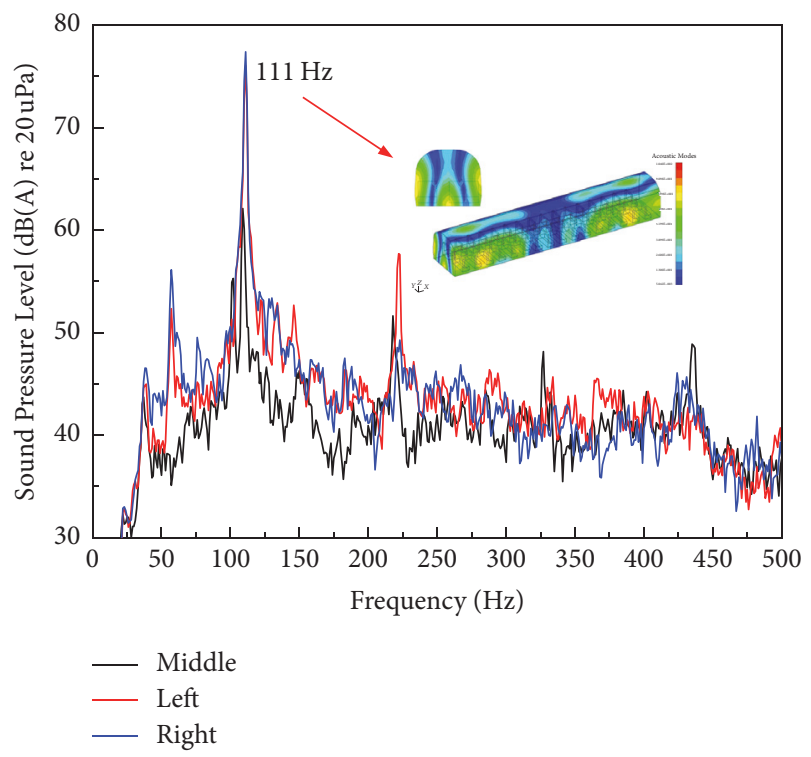

FIGURE 6: Frequency spectra of noise at one end of the coach.

\subsection{The Approach and Procedure}

2.2.1. Gathering of Basic Information and Subjective Perception of the Noise. The first step to deal with a noise issue is to collect basic information and subjective perceptions of the noise, such as train type, where (including track type), when, and at what speed the issue occurs, what the noise sounds like (a number of descriptions can be given for the noise issue owner to select in case that he or she is not willing, or feeling difficult, to give his/her descriptions in writing), and where the listening is made. To help gather and accommodate such information, a well-designed and standardized Excel worksheet is sent to the issue owner to fill the form and then send it back. The form should be designed in such a way that it uses as few jargons as possible, that most questions can be answered by selecting multiple choices instead of by writing sentences, and that instructions are provided for the owner to record a sound and video using his/her mobile phone. Information gathered in this stage is used for initially assessing the issue and also for planning test and measurement.

2.2.2. Regeneration and Professional Perception of the Noise. Before deploying measurement device installation, the train 


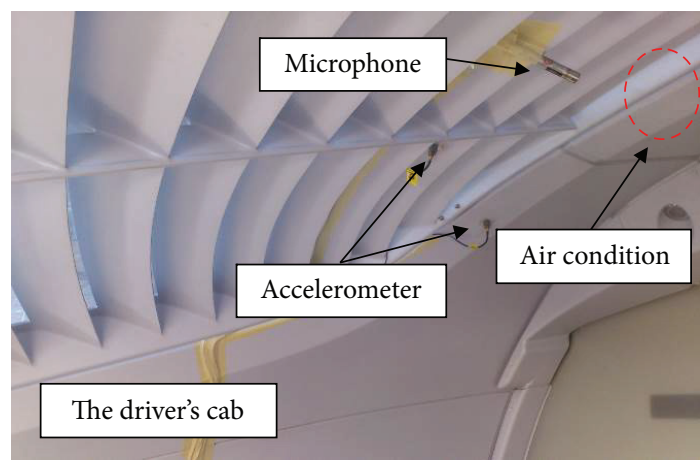

FIGURE 7: Abnormal interior noise in a driver's cab of a high-speed train.

should be run at the same condition as when the noise issue was reported, in order to regenerate the noise. If the noise occurs, subjective perception of the noise by an expert would be useful. Sometimes just at this stage the root cause of the noise can be identified, for example, for the switch door assembly noise issue described in Section 2.1. If the noise cannot be regenerated, then the issue can be suspended until it occurs again.

2.2.3. Test and Noise and Vibration Measurement. In most of the cases, just by listening cannot resolve the noise issue, and test and measurement have to be performed to generate sufficient data to analyze. Testing and measuring in a high-speed train involve a number of parties which need to be coordinated by some sort of authorities. Therefore, the test and measurement plan must be designed in such a way that they do not jeopardize safety, that they cause minimum interruption to train operation, and that they are sufficient to resolve the issue. The following objectives must be achieved by the test:

(1) Regeneration of the issue: if the noise issue cannot be reproduced, then all the data measured during the test would be irrelevant to the noise issue.

(2) Sound pressure time history at the noisy location within a coach: sound pressure time history at the noisy location must be measured to determine its frequency characteristics, and at the same time to identify the problematic frequency either by subjective assessment or by frequency contribution analysis. If no location can be identified to be the noisiest, then the microphone should be just positioned at the middle of the coach and $1.2 \mathrm{~m}$ above the floor.

(3) Area contribution to the sound pressure at the noisy location: since sound pressure at the noisy location can be contributed from the front and rear ends of the coach, the left and the right side walls, and from the roof and floor (all of them are teamed areas in this paper), measured data must be able to provide opportunities to rank contributions from these areas for different frequency bands, broad or narrow. Both a spherical microphone array and a planar sound intensity probe array can be used to achieve such an objective.
(4) Vibration measurement: each area may be thought to be a source for the noisy location. Noise in each area can be induced by different mechanisms. The mechanisms can be vibration and structural radiation (vibroacoustic), or sound propagation through gaps or holes within or behind that area, or both. To identify the actual mechanism, vibration of the inner surface of the area should be measured.

(5) Measurement at a number of train speeds different (higher or lower) from the speed at which the noise issue is filed: since the root cause of the noise issue may be related to train speed, measured data at different speeds may provide clues for the root causes through order analysis or other analyses. Therefore, measurement listed in (1) to (4) should be repeated for different train speeds.

2.2.4. Data Analysis and Root Cause Determination. What kinds of data analysis should be performed depends on the nature of the issue and also on the experience of the one who is dealing with the issue. Section 3 gives an illustration as to what data analysis may be carried out.

2.2.5. Correction Measures and Effects. Once the root causes are known, correction measures can be designed and implemented. The effect of the measures should be assessed subjectively and objectively. Ideally the measurement configuration should be the same as that used in Section 2.2.3 when assessment is done objectively, so that comparison can be made straightforwardly. Assessment should be also done for a number of other train speeds.

The above steps are depicted in Figure 8 as a flowchart. The black " $\downarrow$ " connecting two boxes indicates that the following step is necessary, and the red " $\downarrow$ " indicates that whether the following step is necessary or not depends on the results of the previous step.

\section{A Case Study for a Particular Noise Issue}

3.1. Description of the Noise Issue. The high-speed train, which has the abnormal interior noise issue in the VIP cabin, consists of 8 coaches. Its two end coaches are numbered as TC01 and TC08, respectively. The two VIP cabins are marshaled in the TC01 and TC08; see Figure 9 in the next section. The railway track is ballasted with the sleeper spacing being $0.6 \mathrm{~m}$. When the high-speed train was operationally tested at $250 \mathrm{~km} / \mathrm{h}$, it was noticed by the train staff that the VIP cabin of TC08 is much noisier than that of TC01, especially in the middle section of the VIP. We were called to have a look at the issue and found it difficult to identify any special source which made one VIP cabin much noisier than the other just by listening.

3.2. Measurement Configuration. Figure 9 shows the measurement points in the two VIP cabins of the high-speed train, where two red boxes with dashed boundaries represent the VIP cabins, "๑" refers to acoustic measurement points, and "ø" denotes vibration measurement points. Each VIP cabin has a microphone (B\&K 4190) and three accelerometers 


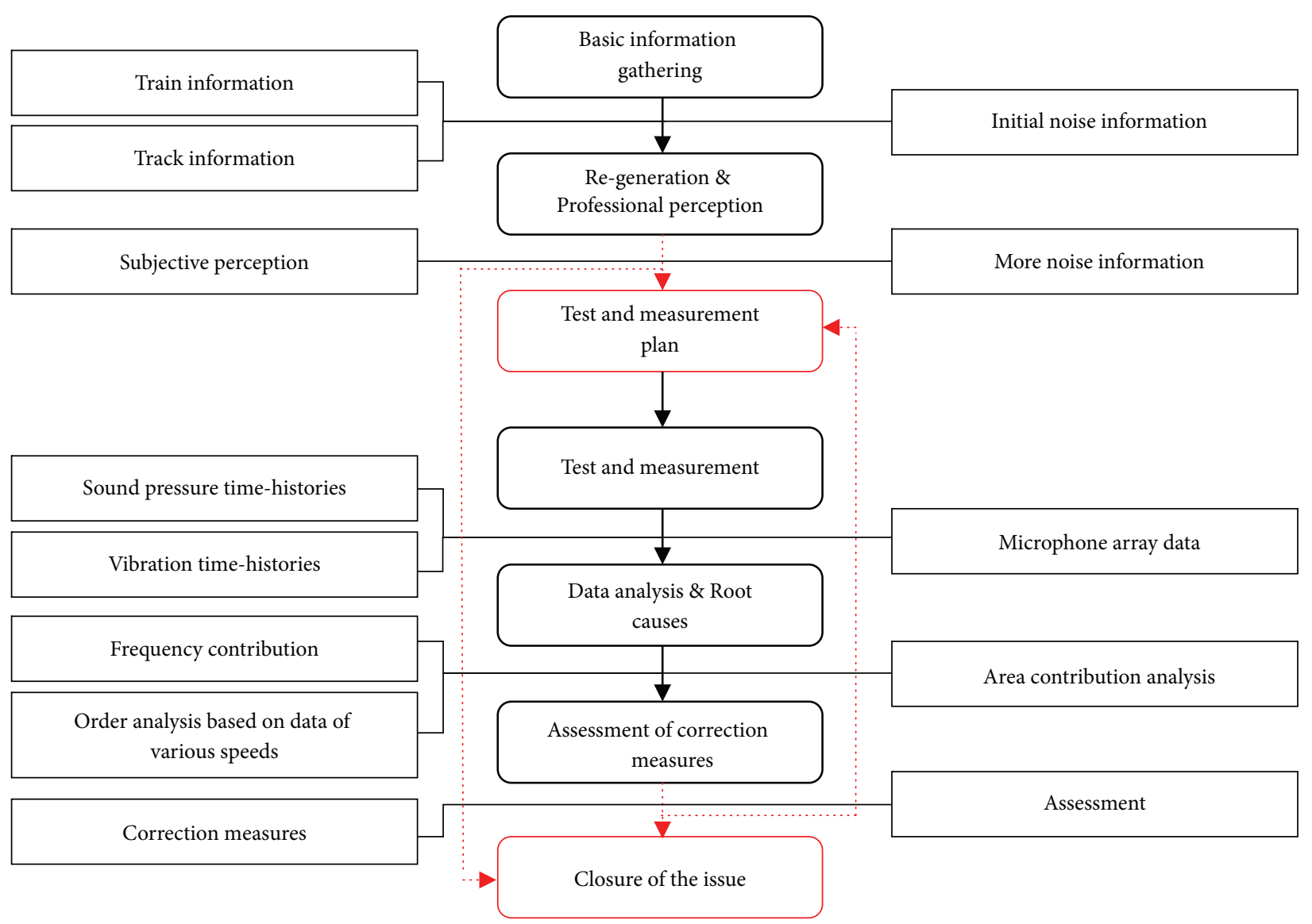

FIGURE 8: The approach and procedure to identify sources of abnormal interior noise for a high-speed train.

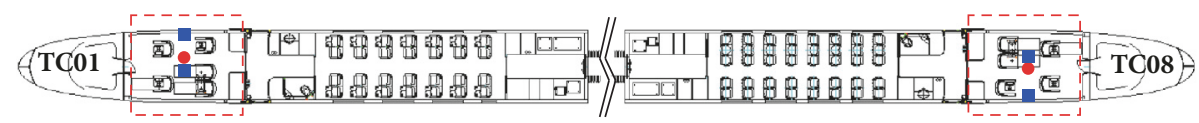

FIGURE 9: Measurement points in the two VIP cabins of a high-speed train.

(B\&K 4508). The microphone is positioned at a height of $1.2 \mathrm{~m}$ above the interior floor in the middle of the VIP cabin and used for measuring the interior noise, and the accelerometers are glued on the interior floor, the sidewall, and the roof to measure accelerations in directions normal to the surfaces. All accelerometers are glued on the panels and positioned within the same cross-section. It should be noted that if the test condition permits, the usage of more accelerometers would improve the quality. Moreover, a spherical microphone array (B\&K WA1565W004) is used to measure data for area contribution analysis in the two VIP cabins. The array is positioned with its center at the same point as the microphone (in other words, the array center is also at a height of $1.2 \mathrm{~m}$ above the interior floor). It is noted that array measurement is done separately. The array is made up of 50 microphones and 12 cameras and the diameter of the array is $19.5 \mathrm{~cm}$, acoustically much smaller than the dimensions of the cabin. Test site photographs are shown in Figure 10.

Measurement for a cabin is performed when the vehicle with the cabin is used as the head car. Moreover, it is carried out with the train running at the same track section when comparing results from TC01 to TC08. The tests were carried out in special journeys without passengers.

3.3. Frequency Contribution Analysis. Figure 11 shows the measured interior noise results from the microphone, overall level, and frequency spectrum in 1/3 octave bands, of the two VIP cabins when the train is running at $250 \mathrm{~km} / \mathrm{h}$. It can be seen that the overall SPL of TC01 is $62.7 \mathrm{~dB}(\mathrm{~A})$, while that of TC08 is $69.7 \mathrm{~dB}(\mathrm{~A}), 7 \mathrm{~dB}(\mathrm{~A})$ higher. It is also seen that noise in TC08 has the highest peak at $125 \mathrm{~Hz}$, about $13 \mathrm{~dB}(\mathrm{~A})$ higher than that of TC01 at the same center frequency.

Figure 12 shows contributions to the overall level of each $1 / 3$ octave band, calculated using

$$
\alpha_{i \text { th band }}=\left(\frac{p_{i \text { th band }}^{2}}{\sum p_{i \text { th band }}^{2}}\right) \times 100 \%,
$$

where $p_{i \text { th band }}$ is the effective sound pressure in the $i$ th $1 / 3$ octave band. 


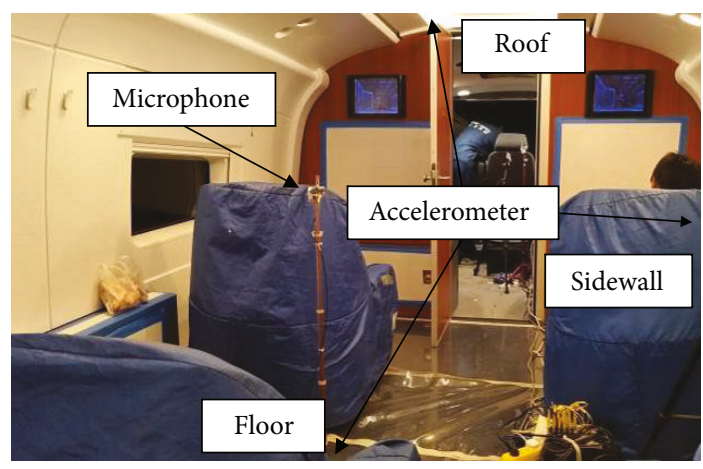

(a) Noise and vibration measurement

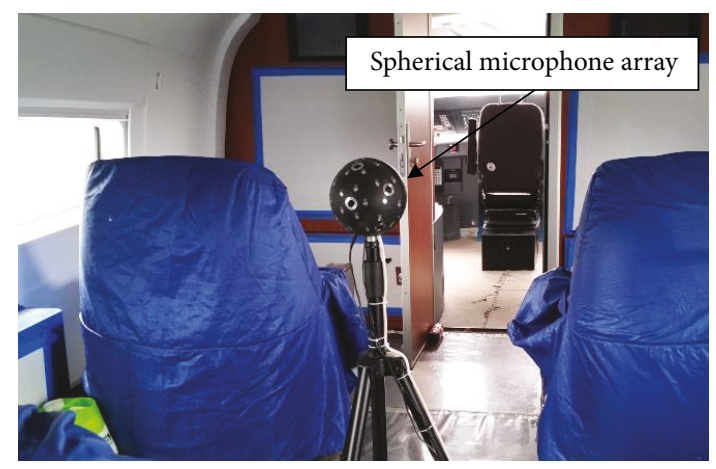

(b) Noise source identification

FIGURE 10: Test photographs of noise and vibration in the VIP cabins.

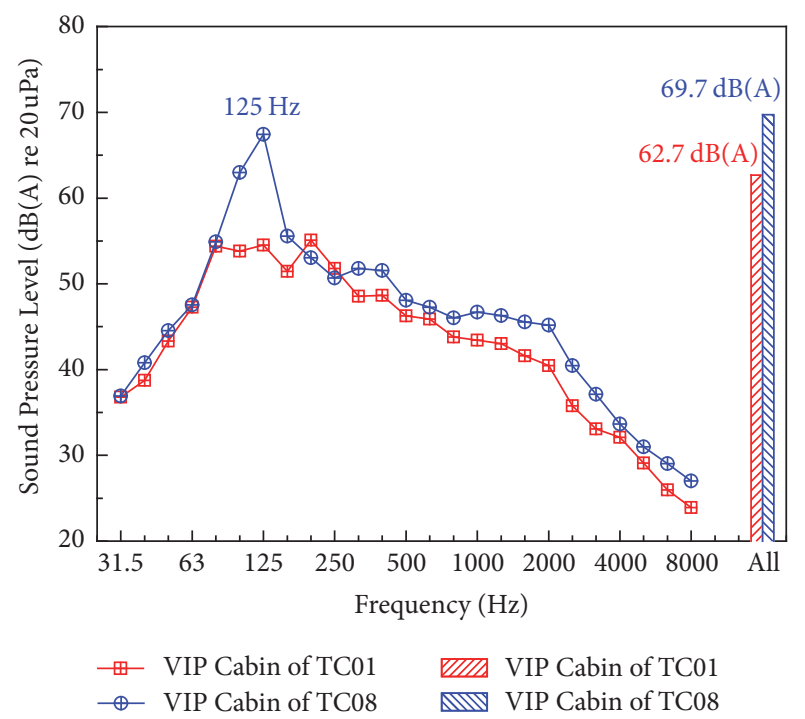

Figure 11: Noise test results in the two VIP cabins.

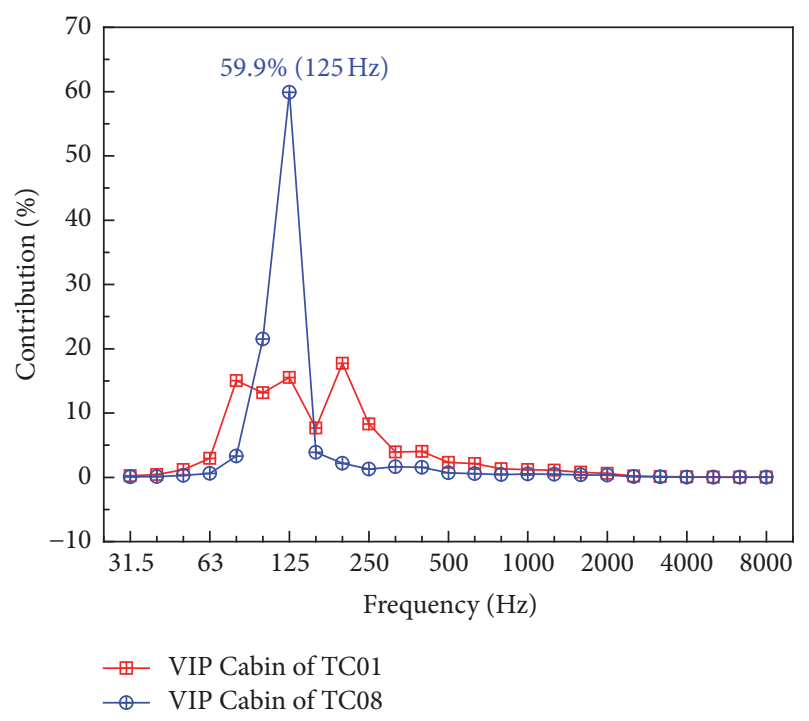

FIGURE 12: Noise contribution in $1 / 3$ octave bands.

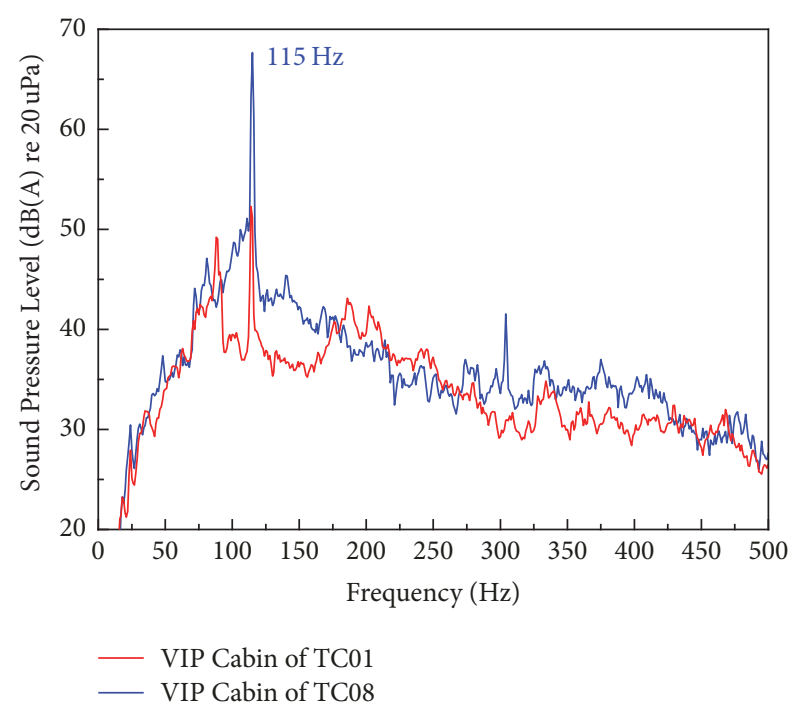

FIGURE 13: Narrow band frequency spectra of noises in the two VIP cabins.

From Figure 12, noise contribution ratio of the $1 / 3$ octave band centered at $125 \mathrm{~Hz}$ in TC08 is $59.9 \%$. It also can be seen that the second highest noise contribution ratio is from the $1 / 3$ octave band centered at $100 \mathrm{~Hz}$, but only $21.5 \%$. Contributions from other $1 / 3$ octave bands are all below $5 \%$. However, the frequency characteristics are quite different for TC01. For this cabin, the $1 / 3$ octave bands centered at $80 \mathrm{~Hz}, 100 \mathrm{~Hz}, 125 \mathrm{~Hz}$, and $200 \mathrm{~Hz}$ are main contributors, but each is between $15 \%$ and $20 \%$. Therefore, it can be concluded that noise in the $1 / 3$ octave band centered at $125 \mathrm{~Hz}$ is critical to the overall SPL in TC08.

Figure 13 further shows the narrow band frequency spectra of noises in the VIP cabins of TC01 and TC08. For TC08, the highest peak is at $115 \mathrm{~Hz}$. Although a peak is also present at this frequency for TC01, its value is $17 \mathrm{~dB}(\mathrm{~A})$ lower. Moreover, noise levels from $100 \mathrm{~Hz}$ to $170 \mathrm{~Hz}$ in TC08 are higher than those in TC01.

Figure 14 shows the Campbell plot of SPL in TC08, with the vertical axis indicating the rotating speed (tacho signal) 


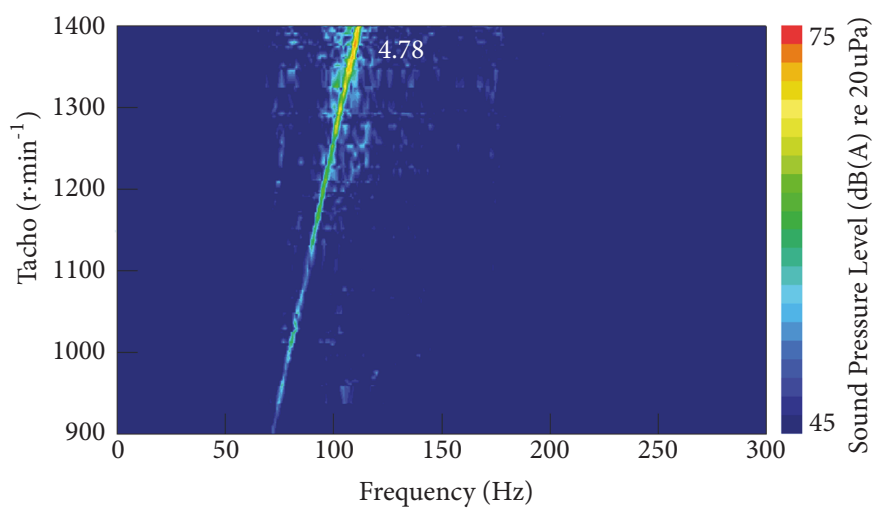

FIgURE 14: Noise order spectrum of the VIP cabin in TC08.

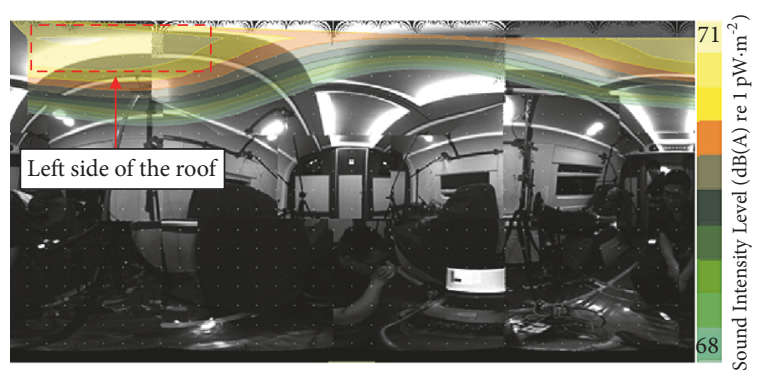

FIGURE 15: Noise source identification result of the VIP cabin in TC08 $(125 \mathrm{~Hz})$.

of the wheel and the horizontal axis indicating frequency. The relationship between the wheel rotating speed and train speed is given by

$$
T=\frac{v}{\pi d}
$$

where $T$ is the rotating speed, $v$ is the train speed, and $d$ is the diameter of the wheel. Here $d=920 \mathrm{~mm}$.

There is a highlighted straight line which is of 4.78 order in terms of the wheel speed, indicating that the problematic frequency is proportional to the rotation speed of the wheel, or equivalently, to the train speed. Running at $250 \mathrm{~km} / \mathrm{h}$, the frequency is $115 \mathrm{~Hz}$, just identical to the sleeper passing frequency. Since the rail usually has discrete supports, the track "stiffness" varies periodically within each sleeper span leading to additional excitation at sleeper passing frequency. The frequency can be verified using

$$
f=\frac{v}{\lambda}
$$

where $\lambda$ is the sleeper spacing.

At this point, it can be concluded that TC08 is noisy which is caused by a much higher component at the sleeper passing frequency.

3.4. Area Contribution Analysis. Area contribution analysis is calculated based on the beamforming principle [19-21]. Figure 15 shows the area contribution results on the spherical surface just allowed by the cabin interior space in the $1 / 3$ octave band centered at $125 \mathrm{~Hz}$ in TC08. The train speed is $250 \mathrm{~km} / \mathrm{h}$. The background photograph is the VIP cabin interior (see Figure 10(b)). The color indicating sound intensity level of which the range is $3 \mathrm{~dB}(\mathrm{~A})$.

From Figure 15, the noise source in $1 / 3$ octave band centered at $125 \mathrm{~Hz}$ in TC08 is mainly located on the left side of the roof. In order to obtain the contribution of each area to the total noise of the receiving point (position of the microphone), the VIP cabin is divided into six areas, which, respectively, correspond to the roof, the left sidewall, the right sidewall, the floor, the front, and rear of the cabin, as shown in Figure 16.

Then the contribution ratios of different areas of the cabin in different frequency bands are calculated by using

$$
\begin{aligned}
\alpha_{i \text { th band, } j \text { th source }}= & \left(\frac{W_{i \text { th band }, j \text { th source }}}{\sum_{\text {sources }} W_{i \text { th band }, j \text { th source }}}\right) \\
& \times 100 \%,
\end{aligned}
$$

where $W_{i \text { th band, } j \text { th source }}$ is the sound power of the $i$ th $1 / 3$ octave band and the $j$ th area.

Figure 17 shows the noise area contributions in different $1 / 3$ octave bands in TC 08 . It can be seen that contributions of the roof, the left sidewall, the right sidewall, the floor, the front, and the rear in each band are similar to each other for bands with frequency centered above $200 \mathrm{~Hz}$. However, in $1 / 3$ octave bands centered from $50 \mathrm{~Hz}$ to $125 \mathrm{~Hz}$, noise contribution of the roof is much higher than those of other areas except at $63 \mathrm{~Hz}$ of the floor. Especially in $1 / 3$ octave band centered at $125 \mathrm{~Hz}$, which is the peak value band, noise contribution ratio of the roof is $53 \%$. However, the second highest contribution ratio is only $19 \%$ from the floor. As a result, the roof plays a decisive role in the total noise of TC08.

Figure 18 shows area contribution results for TC01 with the train speed being $240 \mathrm{~km} / \mathrm{h}$. Since we only have one spherical array system and there are some other testes in the other coaches of the high-speed train, when identified noise source in TC01 the speed is limited to $240 \mathrm{~km} / \mathrm{h}$. Figure 18(a) shows the noise distribution in the $1 / 3$ octave band centered at $125 \mathrm{~Hz}$, and Figure 18(b) indicates that at $100 \mathrm{~Hz}$. From Figure 18, the maximum contributors in TC01 for the $1 / 3$ 


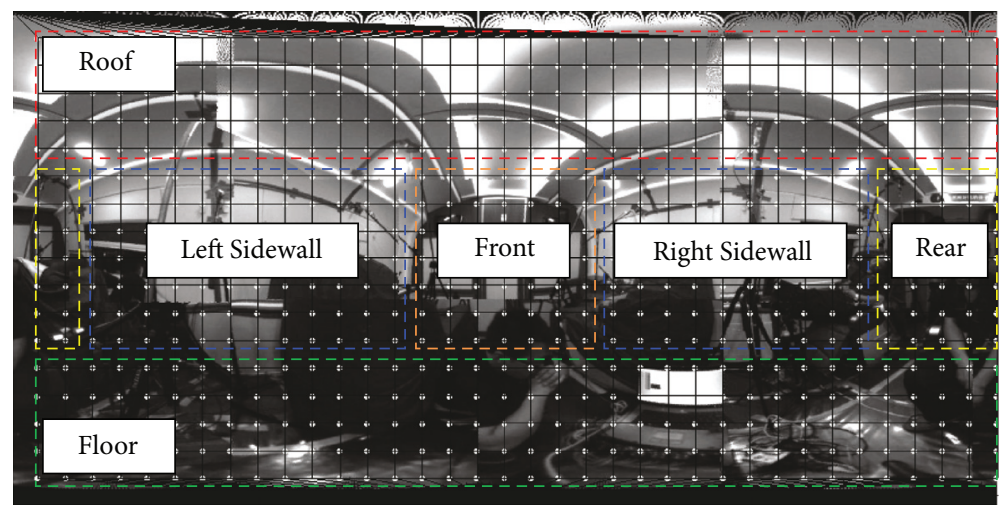

FIGURE 16: Divided areas of the VIP cabin.

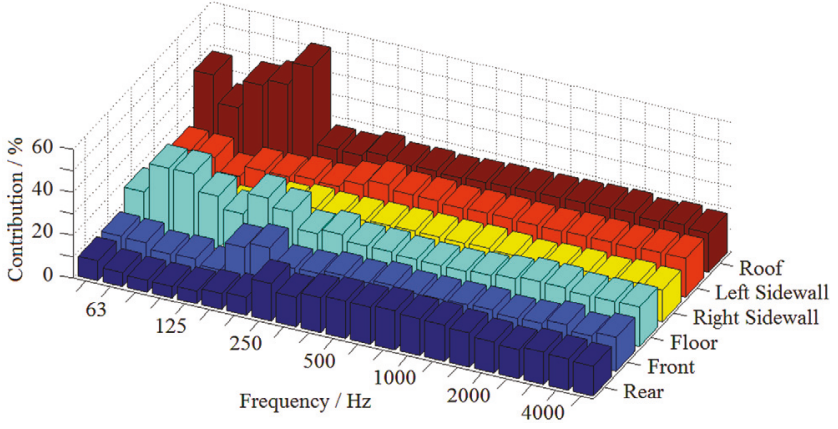

FIGURE 17: Area contributions of TC08 in different 1/3 octave bands.

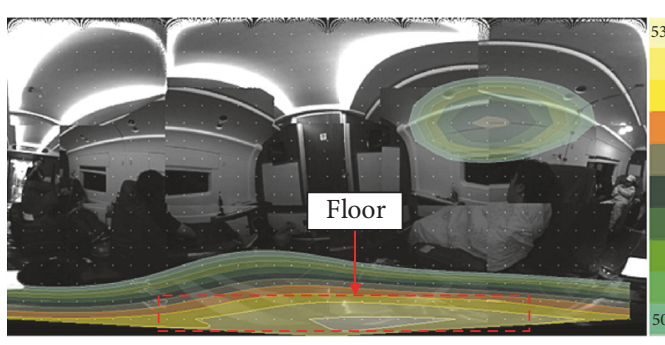

(a) In $1 / 3$ octave band centered at $125 \mathrm{~Hz}$

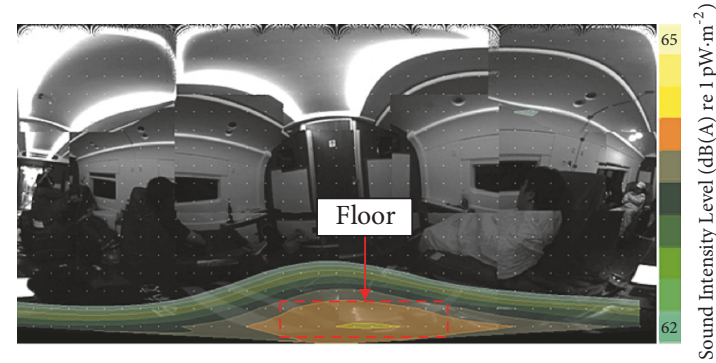

(b) In $1 / 3$ octave band centered at $100 \mathrm{~Hz}$

FIGURE 18: Area contribution results of the VIP cabin in TC01.

octave bands centered at $125 \mathrm{~Hz}$ and $100 \mathrm{~Hz}$ are the floor, different from TC08.

Figure 19 shows the noise area contributions in different $1 / 3$ octave bands in TC01. It can be seen that in $1 / 3$ octave bands centered from $100 \mathrm{~Hz}$ to $250 \mathrm{~Hz}$, contributions from the floor are the highest, followed by the front and the roof.

Up to this point, it can be concluded that the noise issue in TC08 is attributed to an area (the red area) which is located on the roof of the cabin. A photo of the red area is shown in Figure 20. However, there are a number of possibilities: (1) that the area produces noise by too strong vibration and radiation of a panel and that vibration is caused by structure-borne transmission or resonance; (2) that the area produces noise by too strong vibration and radiation of a panel and that vibration is caused by sound pressure behind the panel; (3) that the area produces noise by allowing sound generated somewhere to propagate through it freely (sound leakage); and (4) that any combination of the above presents simultaneously with similar importance.

At this stage, one naturally thinks about disassembling the structure of the roof to see what is wrong there. However, by doing that at this stage would destroy some of the possibilities listed above and make root source identification more difficult. For different sound transfer paths, the noise control methods are quite different. For example, if there is a sound leakage in the roof, it is advised to do seal processing immediately. However, if there are vibration and sound radiation problems to be found, it is advised to do 


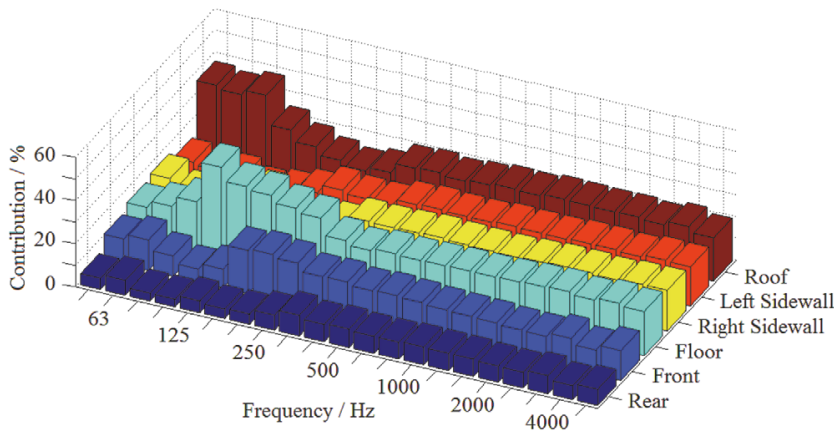

FIGURE 19: Area contributions of TC01 in different 1/3 octave bands.

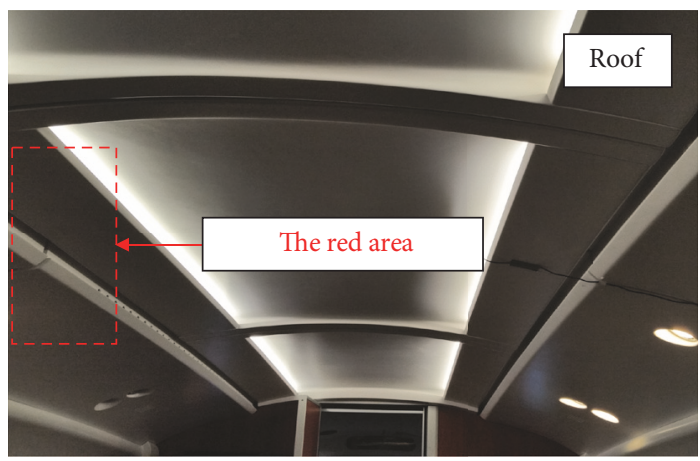

FIGURE 20: Noise source location on the roof of TC08.

vibration reduction. Further data analysis is preferred, as described below, in order to pinpoint the actual causes of the noise issue.

3.5. Determination of Root Causes. Figures 21 and 22 show the narrow band frequency spectra of accelerations measured at different points (on panels) of the two VIP cabins at $250 \mathrm{~km} / \mathrm{h}$.

From Figure 21, the accelerations of the roof, the sidewall, and the floor in TC08 are all having a peak at $115 \mathrm{~Hz}$. The peak of the roof is the highest and that of the sidewall is the lowest. However, in TC01, although accelerations are also peaked at $115 \mathrm{~Hz}$, the peak of the floor is the highest while that of the roof is the lowest, as shown in Figure 22. At $115 \mathrm{~Hz}$, the acceleration amplitude of the roof of TC08 is $6.7 \mathrm{~dB}$ higher than that of TC01, while the acceleration amplitudes of the sidewall and the floor of TC08 are 3-4 dB lower than those of TC01.

Now there are three possibilities for the red area in Figure 20 which show as high noise level: (1) it is produced by the strong vibration and sound radiation of the roof inner panels; (2) it is produced by sound leakage through, and scattering by, the panel gaps; (3) both.

As indicated in Sections 2.1 and 2.2.3, the actual situation may be identified through sound and vibration data measured at different train speeds. Figure 23 shows the noise spectra of TC08 and TC01 at $200 \mathrm{~km} / \mathrm{h}$ (for safety reason, the train is not allowed to test at a speed higher than $250 \mathrm{~km} / \mathrm{h}$ ). Figures 24, 25, and 26 indicate the acceleration spectra of the roof, the sidewall, and the floor of the two VIP cabins, respectively, at $200 \mathrm{~km} / \mathrm{h}$.

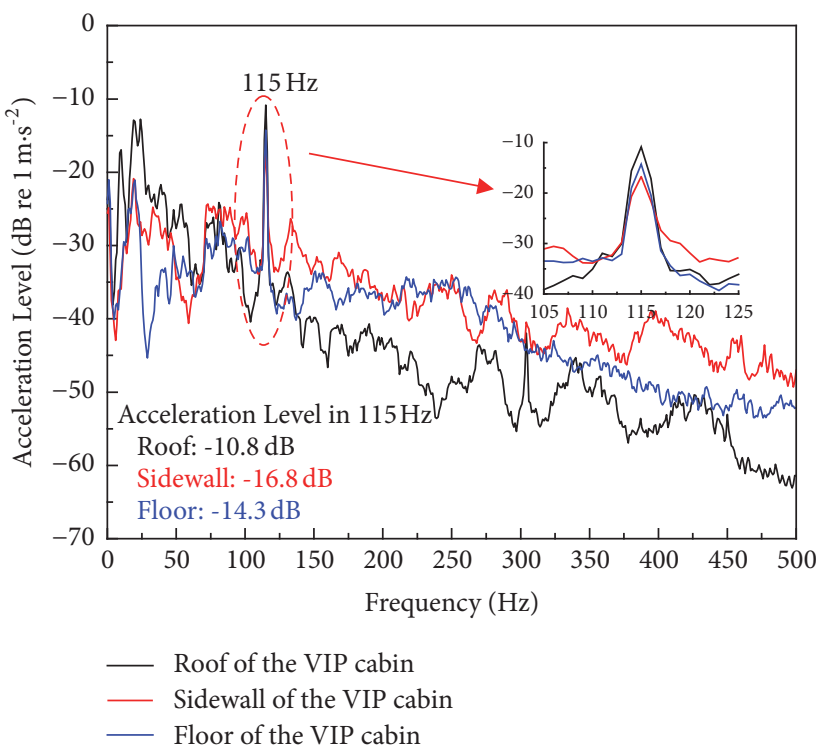

FIGURE 21: Narrow band frequency spectra of accelerations in TC08.

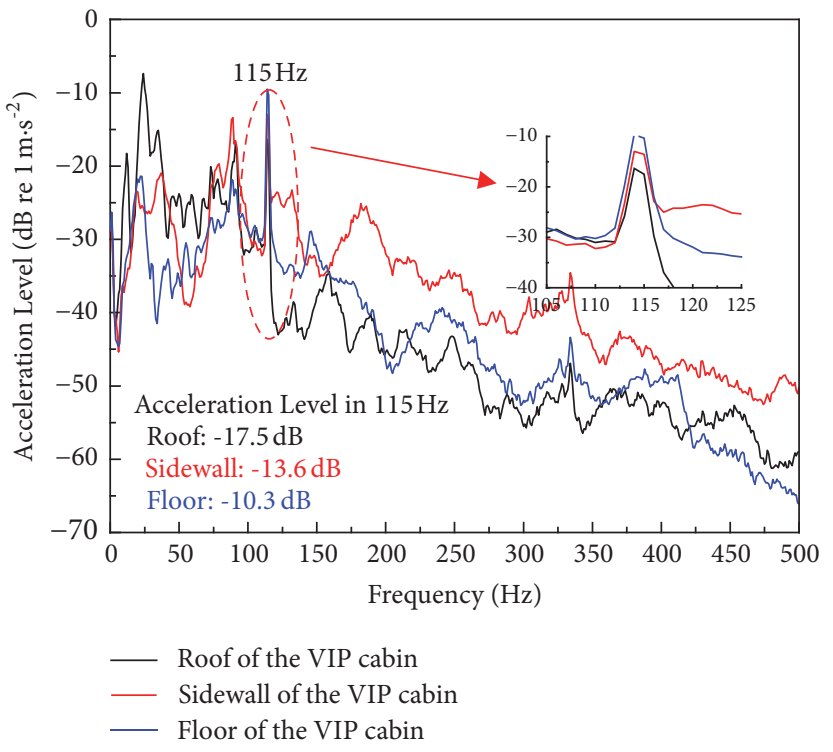

FIGURE 22: Narrow band frequency spectra of accelerations in TC01.

Figure 23 indicates that the highest peak frequency is $91 \mathrm{~Hz}$ which is the sleeper passing frequency at $200 \mathrm{~km} / \mathrm{h}$. At this frequency, as indicated from Figures 24-26, the acceleration levels of the roof, the sidewall, and the floor of TC08 are much lower than those of TC01. However, from $91 \mathrm{~Hz}$ to $125 \mathrm{~Hz}$, the noise SPL of TC08 is still higher than that of TC01, or least similar. If the sound is purely from panel radiations, then at $91 \mathrm{~Hz}$, SPL in TC08 should have been much lower than that in TC01.

Thus, sound leakage and scattering can be assumed behind the red area. Why at $200 \mathrm{~km} / \mathrm{h}$, the leaked sound pressure does not excite strong vibration for the roof panel may be explained to be that the sound pressure is not high enough to exceed other excitation mechanisms. However, at $250 \mathrm{~km} / \mathrm{h}$, as wheel/rail noise and vibration generated by 


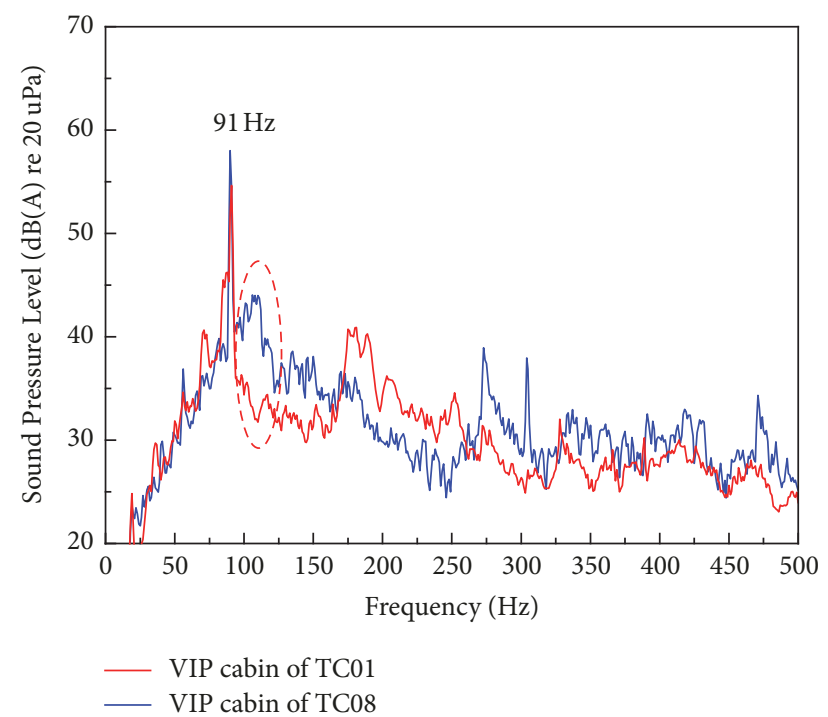

FIGURE 23: Narrow band frequency spectra of noises in the two VIP cabins.

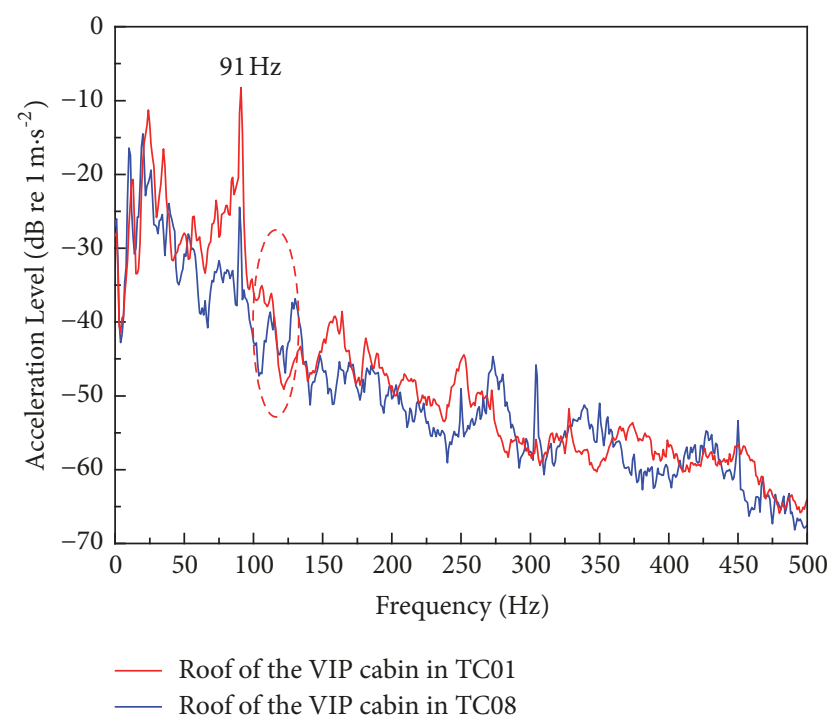

FIGURE 24: Narrow band frequency spectra of acceleration of the roofs.

sleeper passing of the train becomes much stronger, the leaked sound pressure becomes the dominant excitation to the roof panel. The red area is a combined effect of sound leakage, scattering, and panel radiation. There are two ways for sleeper passing transfer to the roof: one is vibration from the bogie area to the roof through the car-body structure and the other is noise from the bogie area to the roof through the gaps between the exterior car-body and the inner panels. Since there could be sound leakage and scattering behind the roof, the second transfer path would be dominant.

Based on the work reported above, the roof panel of TC08 was disassembled. Figure 27 shows the details of the inner roof structure of TC08.

It can be seen from Figure 27(a) that, on the left side of the roof, there is an opening of $300 \mathrm{~cm}^{2}$ for running cables,

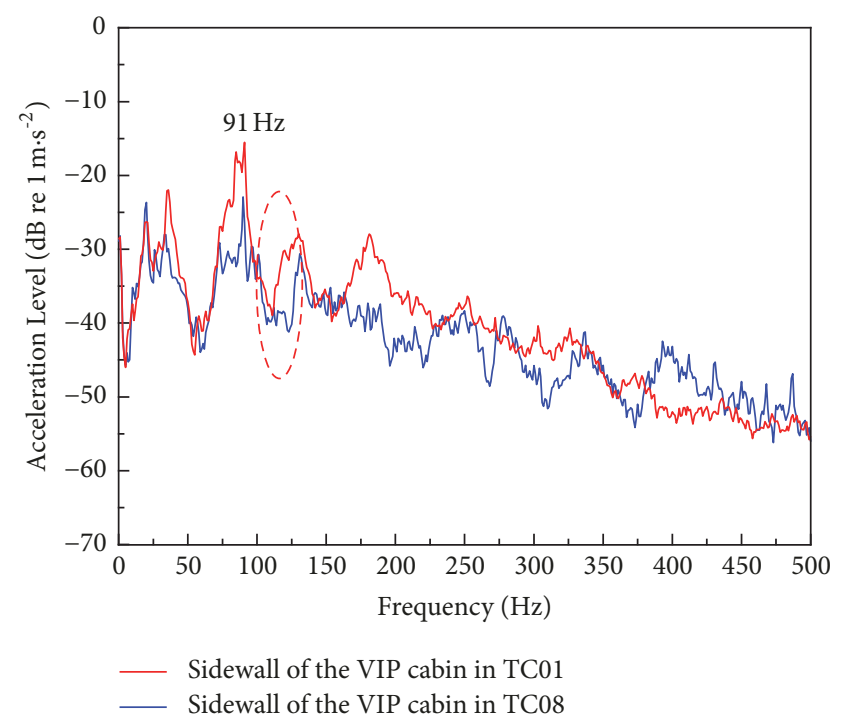

FIGURE 25: Narrow band frequency spectra of acceleration of the sidewalls.

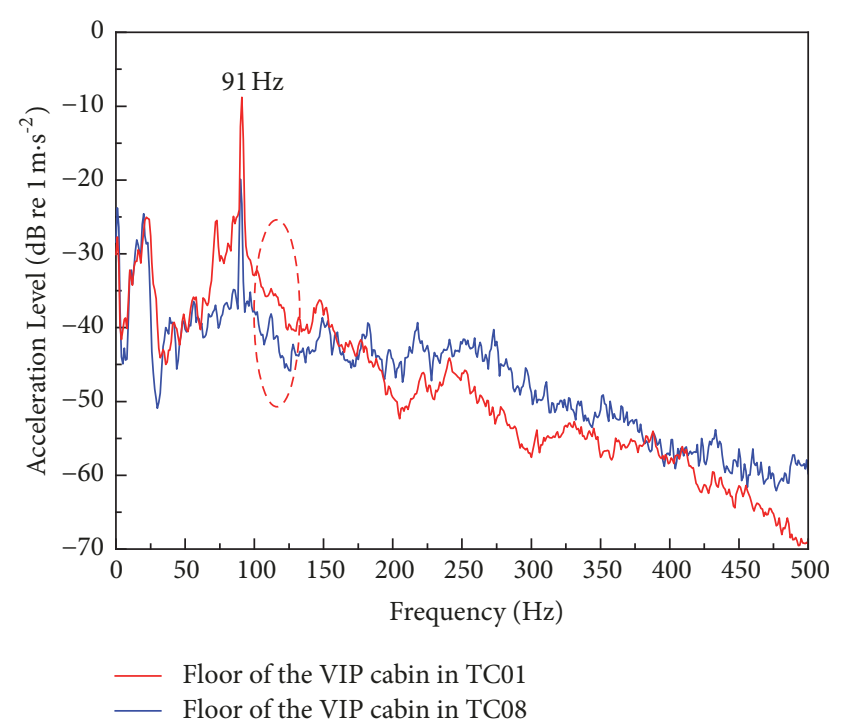

FIgURE 26: Narrow band frequency spectra of acceleration of the floors.

and such an opening is not present on the right-hand side (Figure 27(b)). The opening should have been blocked using sound insulation material to prevent sound propagation through the opening into the cabin. It is this defeat that allows external noise to enter the cabin, especially for the wheel/rail noise and vibration caused by the sleepers passing of the train.

3.6. Correction Measures and Effects. The opening is now mended so that it becomes normal as the right-hand side shown in Figure 27(b). After mending the damaged roof of TC08, the field test is carried out again to check the effect of the correction. Figure 28 shows the measured noise results of the two VIP cabins at $250 \mathrm{~km} / \mathrm{h}$.

From Figure 28, the overall SPL in TC08 is $65.9 \mathrm{~dB}(\mathrm{~A})$, while that in TC01 is $65.0 \mathrm{~dB}(\mathrm{~A})$. The difference in overall 

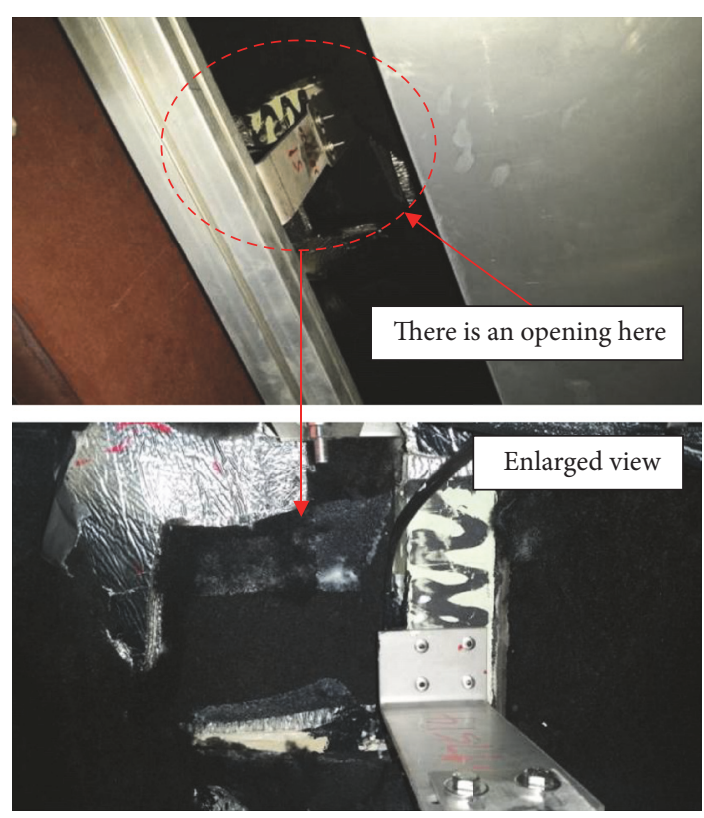

(a) Damaged left side of the roof
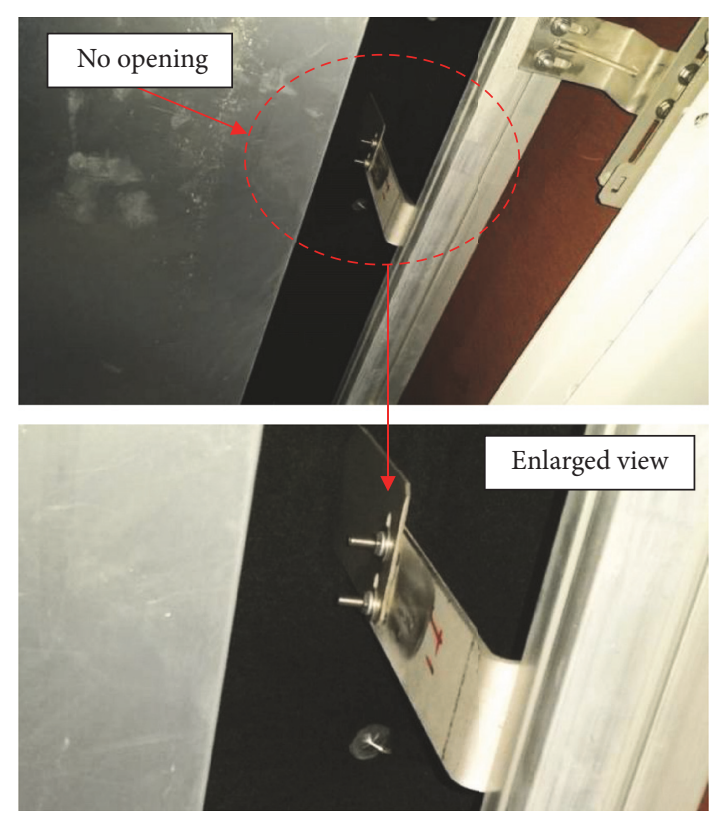

(b) Normal right side of the roof

FIgURE 27: Inner roof structure of the VIP cabin in TC08.

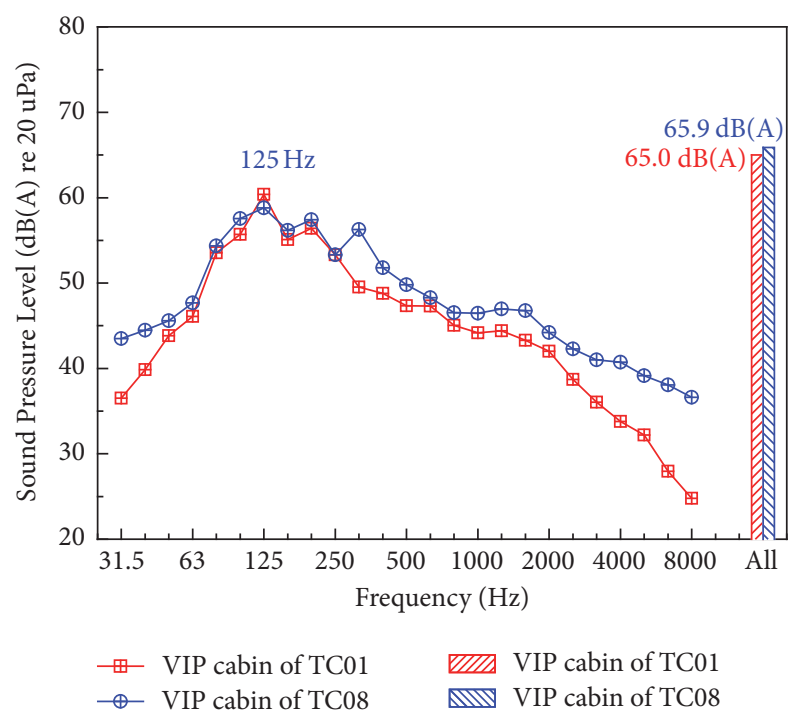

FIGURE 28: Noise test results in the two VIP cabins after the roof mending.

level is now less than $1 \mathrm{~dB}(\mathrm{~A})$. The difference between the peak values at $125 \mathrm{~Hz}$ is even much smaller. However, it can be seen from Figure 28 that across all the 1/3 octave bands, TC01 is quieter than TC08, although these two VIP cabins are constructed based on the same design and production process. From Figure 11 it is also seen that, apart from the problematic frequency bands, TC01 is quieter than TC08. These observations can be explained partly by variations between products of the same design and partly by measurement uncertainty. A measurement system analysis (MSA) may be required to quantify relative contributions.

\section{Conclusion}

This paper presents a measurement-based approach by performing a detailed investigation into a particular "abnormal interior noise" issue occurring in a Chinese high-speed train running at $250 \mathrm{~km} / \mathrm{h}$. Well planned measurements are performed in both the VIP cabins. Sound pressure contributions, either in terms of frequency band or in terms of facing area, are analyzed. Order analysis is also carried out. Based on these analyses, it is found that the problematic frequency is the sleeper passing frequency of the train, and an area (the red area) on the roof contributes the most. In order to determine what causes that area to be the main contributor without disassembling the structure of the roof, measured noise and vibration data for different train speeds are further analyzed. It is then reasoned that the red area is the main contributor caused by sound pressure behind the panel. Up to this point, panels of the roof are removed, revealing that a hole of $300 \mathrm{~cm}^{2}$ for running cables is presented behind the red area without proper sound insulation. After the roof mending, the noise level of TC08 is greatly lowered. The present work illustrates that small defect in the structure installation of high-speed train cabins can cause a high-level interior noise issue, and this study can provide a basis for abnormal interior noise analysis and control of high-speed trains.

\section{Data Availability}

The data used to support the findings of this study are not being made available.

\section{Conflicts of Interest}

The authors declare that they have no conflicts of interest. 


\section{Acknowledgments}

This work was supported by the National Key R\&D Plan of China (nos. 2016YFE0205200, 2016YFB1200506-08, and 2016YFB1200503-02), the National Natural Science Foundation of China (nos. U1434201 and 51475390), and the Scientific Research Foundation of State Key Laboratory of Traction Power, China (no. 2015TPL_T08). The authors are grateful for Jun Zhang, Yue Wu, Rong Fu, Dan Yao, and Xiaolong Liu (Southwest Jiaotong University, China) for their assistance in this study.

\section{References}

[1] P. W. Eade and A. E. J. Hardy, "Railway vehicle internal noise," Journal of Sound and Vibration, vol. 51, no. 3, pp. 403-415, 1977.

[2] X. S. Jin, "Key problems faced in high-speed train operation," Journal of Zhejiang University-SCIENCE A (Applied Physics and Engineering), vol. 15, no. 12, pp. 936-945, 2014.

[3] N. I. Ivanov, I. S. Boiko, and A. E. Shashurin, "The problem of high-speed railway noise prediction and reduction," Procedia Engineering, vol. 189, pp. 539-546, 2017.

[4] A. Van Beek, M. Beuving, and M. Dittrich, "Rail Sources: State of the Art," Tech. Rep., European Commission, 2002, Harmonoise Report (HAR12TR - 020118 - SNCF10).

[5] P. J. Remington, "Wheel/rail rolling noise, I: theoretical analysis," The Journal of the Acoustical Society of America, vol. 81, no. 6, pp. 1805-1823, 1987.

[6] D. J. Thompson and P.-E. Gautier, "Review of research into wheel/rail rolling noise reduction," Proceedings of the Institution of Mechanical Engineers, Part F: Journal of Rail and Rapid Transit, vol. 220, no. 4, pp. 385-408, 2006.

[7] T. Kitagawa and K. Nagakura, "Aerodynamic noise generated by Shinkansen cars," Journal of Sound and Vibration, vol. 231, no. 3, pp. 913-924, 2000.

[8] K. Nagakura, "Localization of aerodynamic noise sources of Shinkansen trains," Journal of Sound and Vibration, vol. 293, no. 3-5, pp. 547-556, 2006.

[9] C. Mellet, F. Létourneaux, F. Poisson, and C. Talotte, "High speed train noise emission: latest investigation of the aerodynamic/rolling noise contribution," Journal of Sound and Vibration, vol. 293, no. 3-5, pp. 535-546, 2006.

[10] H.-M. Noh, "Noise-source identification of a high-speed train by noise source level analysis," Proceedings of the Institution of Mechanical Engineers, Part F: Journal of Rail and Rapid Transit, vol. 231, no. 6, pp. 717-728, 2017.

[11] Y. Soeta and R. Shimokura, "Survey of interior noise characteristics in various types of trains," Applied Acoustics, vol. 74, no. 10, pp. 1160-1166, 2013.

[12] B. Park, J.-Y. Jeon, S. Choi, and J. Park, "Short-term noise annoyance assessment in passenger compartments of high-speed trains under sudden variation," Applied Acoustics, vol. 97, pp. 46-53, 2015.

[13] R. Fan, Z. Su, G. Meng, and C. He, "Application of sound intensity and partial coherence to identify interior noise sources on the high speed train," Mechanical Systems and Signal Processing, vol. 46, no. 2, pp. 481-493, 2014.

[14] Z. Chu, Y. Yang, and Y. He, "Deconvolution for three-dimensional acoustic source identification based on spherical harmonics beamforming," Journal of Sound and Vibration, vol. 344, pp. 484-502, 2015.
[15] Y. Yang, Z. Chu, L. Shen, and Z. Xu, "Functional delay and sum beamforming for three-dimensional acoustic source identification with solid spherical arrays," Journal of Sound and Vibration, vol. 373, pp. 340-359, 2016.

[16] R. Ström, Operational Transfer Path Analysis of components of a high-speed train bogie, Chalmers university of technology, Göteborg, Sweden, 2014.

[17] J. Zhang, X. B. Xiao, G. Han, Y. Deng, and X. S. Jin, "Study on abnormal interior noise of high-speed trains," in Proceedings of the 11th International Workshop on Railway Noise, pp. 691-698, Uddevalla, Sweden, 2013.

[18] J. Zhang, X. Xiao, J. Han, Q. Sun, G. Han, and X. Jin, "Characteristics of noise distribution at the ends of the coach and acoustic modal analysis of high-speed train," Journal of Mechanical Engineering, vol. 50, no. 12, pp. 97-103, 2014 (Chinese).

[19] E. G. Williams, Fourier Acoustics: Sound Radiation and Nearfield Acoustical Holography, Academic Press, New York, NY, USA, 1999.

[20] B. Rafaely, "Plane-wave decomposition of the sound field on a sphere by spherical convolution," The Journal of the Acoustical Society of America, vol. 116, no. 4 I, pp. 2149-2157, 2004.

[21] I. Cohen, J. Benesty, and S. Gannot, Speech Processing in Modern Communication: Challenges and Perspectives, Springer Berlin Heidelberg, Germany, 2010. 


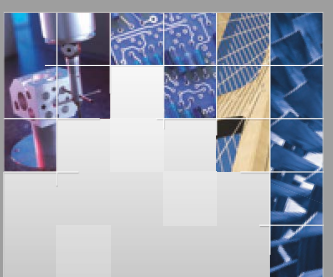

\section{Enfincering}
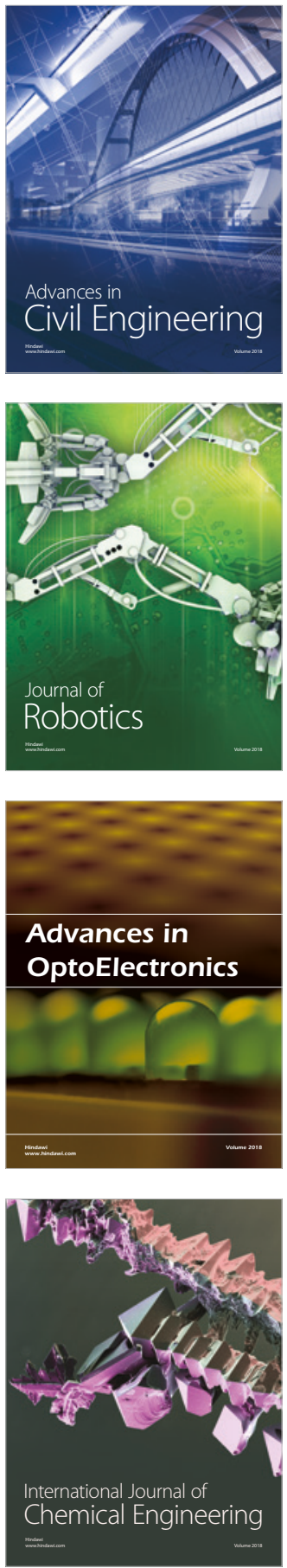

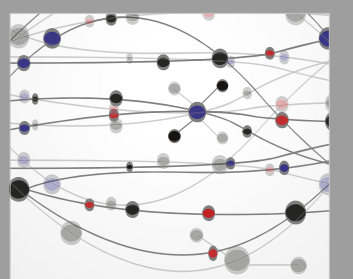

\section{Rotating \\ Machinery}

The Scientific World Journal

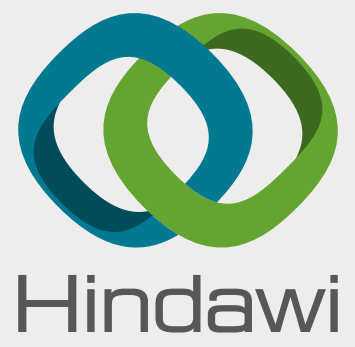

Submit your manuscripts at

www.hindawi.com
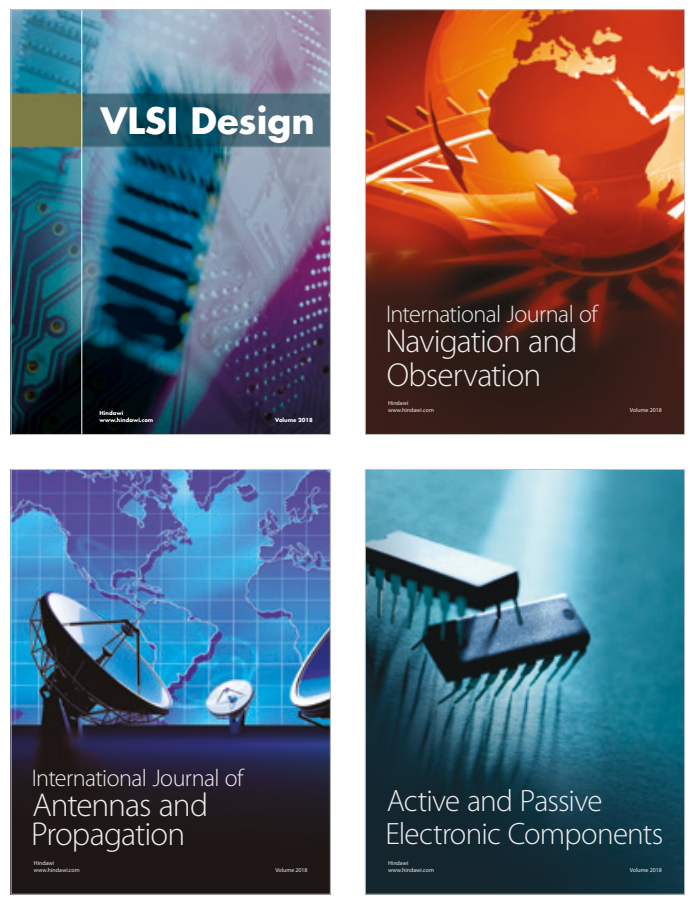
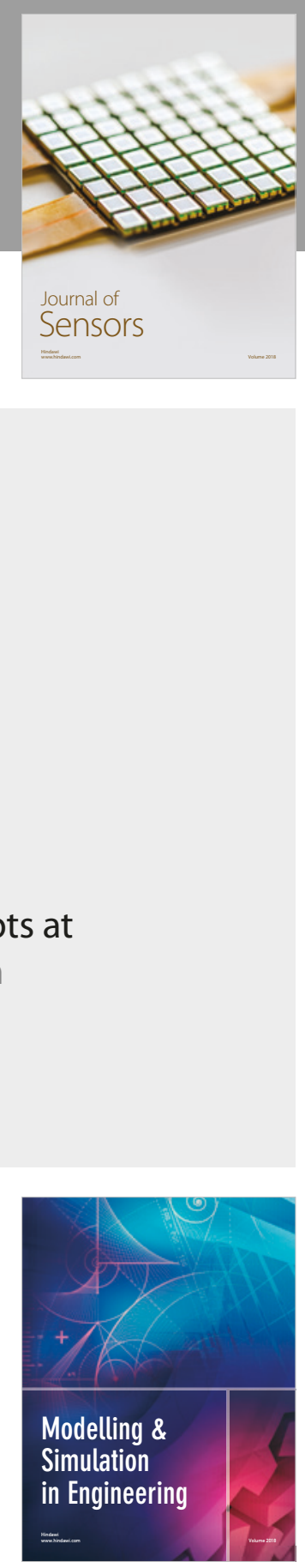

\section{Advances \\ Multimedia}
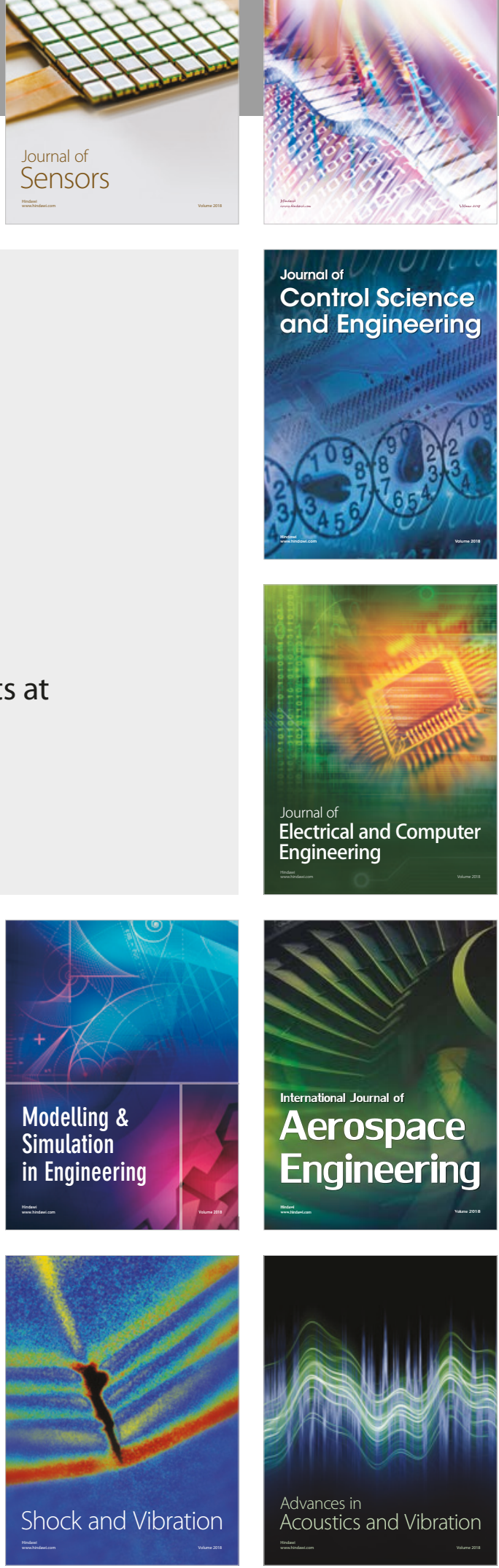